\title{
Classifying Intersex in DSM-5: Critical Reflections on Gender Dysphoria
}

\author{
Cynthia Kraus ${ }^{1}$
}

Published online: 6 May 2015

(c) Springer Science+Business Media New York 2015

\begin{abstract}
The new diagnosis of Gender Dysphoria (GD) in the fifth edition of the Diagnostic and Statistical Manual of Mental Disorders (American Psychiatric Association, 2013) defines intersex, renamed "Disorders of Sex Development" (DSD), as a specifier of GD. With this formulation, the status of intersex departs from prior editions, especially from the DSMIV texts that defined intersex as an exclusion criterion for Gender Identity Disorder. Conversely, GD—with or without a DSD - can apply in the same manner to DSD and non-DSD individuals; it subsumes the physical condition under the mental "disorder." This conceptualization, I suggest, is unprecedented in the history of the DSM. In my view, it is the most significant change in the revised diagnosis, and it raises the question of the suitability of psychiatric diagnosis for individuals with intersex/DSD. Unfortunately, this fundamental question was not raised during the revision process. This article examines, historically and conceptually, the different terms provided for intersex/DSD in the DSM in order to capture the significance of the DSD specifier, and the reasons why the risk of stigma and misdiagnosis, I argue, is increased in DSM-5 compared to DSM-IV. The DSM-5 formulation is paradoxically at variance with the clinical literature, with intersex/DSD and transgender being conceived as incommensurable terms in their diagnostic and treatment aspects. In this light, the removal of intersex/DSD
\end{abstract}

Cynthia Kraus

cynthia.kraus@unil.ch

1 Institute of Social Sciences, Faculty of Social and Political Sciences, University of Lausanne, Quartier Mouline, Geopolis Building, Office 5132, 1015 Lausanne, Switzerland from the DSM would seem a better way to achieve the purpose behind the revised diagnosis, which was to reduce stigma and the risk of misdiagnosis, and to provide the persons concerned with healthcare that caters to their specific needs.

Keywords DSM-5 - Gender identity disorder · Gender incongruence $\cdot$ Gender dysphoria . Disorders of sex development · Intersexuality

\section{Introduction}

The clinical category of "intersex" defined as "physical abnormalities of the sex organs" was introduced in DSM-III in the context of the first formulations of psychosexual "disorders" in gender identity (American Psychiatric Association [APA], 1980, pp. 263-265). In Table 1, I offer a synopsis of the different terms provided for intersex/DSD in the successive DSM texts. The initial classification for gender identity "problems" included two specific diagnoses: Transsexualism for adolescents and adults (Transsexualism), and Gender Identity Disorder of Childhood (GIDC); and a residual diagnosis named Atypical Gender Identity Disorder (Atypical GID). In the DSM classification, residual categories were designed for clinical presentations in patients who did not meet all the criteria of a specific diagnosis, here Transsexualism and GIDC. DSM-III-R (APA, 1987) retained the specific diagnoses of Transsexualism and GIDC, removed Atypical GID, and introduced two new categories: Gender Identity Disorder of Adolescence or Adulthood, Nontranssexual Type (GIDAANT) and Gender Identity Disorder Not Otherwise Specified (GIDNOS).

In DSM-IV (APA, 1994) and DSM-IV-TR (APA, 2000), Transsexualism and GIDC were substituted by the generic category of Gender Identity Disorder (GID) with distinct criteria sets for the two age groups. The DSM-5 diagnosis of 
Gender Dysphoria (GD) is an overarching category that includes two criteria sets: one for Children (302.6), and one for Adolescents and Adults (302.85). GD also includes a DSD specifier for both age groups. Accordingly, the diagnosis comes in two "versions": with or without a DSD.

The changed status of intersex/DSD in DSM- 5 has received little attention so far. It is the least documented of all revisions, and the reasons for this particular change remain unexplained in the "Memo Outlining Evidence for Change in Gender Identity Disorder in the DSM-5" (Zucker et al., 2013). It is even unclear whether or not the inclusion of a DSD specifier is meant to constitute a change. It is omitted in the appendix entitled "Highlights of Changes from DSM-IV to DSM-5" that mentions, however, the addition of a "posttransition specifier" for those adolescents and adults who have successfully transitioned (APA, 2013, pp. 814-815). This omission may suggest that the former is considered a minor change or no change at all.

This article offers a conceptual history of the overlooked new status of intersex/DSD in GD from a critical perspective inspired by feminist theory and the social studies of science and medicine. My discussion is based for the most part on the DSM literature produced during the fourth and fifth revisions, and focuses on how gender identity "disorder" experts conceptualized intersex/DSD in these contexts and beyond. I first discuss the various ways in which intersex/DSD was classified in the successive editions, from DSM-III to DSM-5. I highlight in this manner the unique features of the specifier option compared to earlier formulations, in particular in the DSM-IV texts. I then identify the historical turning points and the conceptual moves that account for these features. I here consider the DSM-5 reports, the revision recommendations, and the specific ways in which the longstanding but key notions of gender incongruence and gender dysphoria have been redefined (or not) so as to "naturalize" the full inclusion of intersex/DSD in the revised diagnosis, incorrectly assuming in the process that such a move is self-evident. At that point, I ask whether GD is an intersex condition. The short answer is no, because the healthcare issues particular to individuals with intersex/DSD are not taken into account. After explaining why, I finally consider how the risk of stigma and misdiagnosis and other classification problems are amplified in DSM-5 compared to DSM-IV, which eventually undermines the applicability of the diagnosis of GD to individuals with intersex/DSD.

\section{Intersex/DSD in the DSM}

Over the years, five distinct statuses have been defined for intersex relative to the various diagnostic categories for gender identity "problems": (1) exclusion; (2) inclusion via Axis III; (3) inclusion allowed in the absence of an exclusion clause; (4) inclusion in the residual category of GIDNOS; (5) finally, full inclusion as a specifier in DSM-5.

\section{Exclusion}

With the notable exceptions of DSM-III-R and DSM-5, the presence of intersex ruled out the specific diagnostic categories for "disorders" in gender identity. Criterion D ("Absence of physical intersex or genetic abnormality") for the diagnosis of Transsexualism in DSM-III, and Criterion C ("The disturbance is not concurrent with a physical condition") for the GID diagnosis in DSM-IV and DSM-IV-TR defined such exclusion clauses (APA, 1980, p. 264, 1994, p. 551, 2000, p. 581). Both DSM-IV and DSM-IV-TR added a further precision emphasizing the "normality" of the sex organs as the somatic condition of possibility for making a GID diagnosis: "Individuals with Gender Identity Disorder have normal genitalia (in contrast to the ambiguous genitalia or hypogonadism [underfunctioning testes or ovaries] found in physical intersex conditions)"(APA, 1994, p. 548, 2000, p. 579).

\section{Inclusion via Axis III}

The possibility of diagnosing intersex individuals - children, adolescents, and adults—-with a gender identity “disorder" existed since DSM-III. The relevant diagnoses were GIDC in DSMIII and DSM-III-R, as well as Transsexualism in DSM-III-R (APA, 1980, p. 265, 1987, pp. 73-74). ${ }^{1}$ Strictly speaking, the specific (not residual) diagnoses of GIDC in DSM-III and DSM-III-R and of Transsexualism in DSM-III-R did not include individuals with intersex. But the "physical disorder" could be linked to a psychiatric diagnosis (coded on Axis I), provided that the clinician resorted to another "dimension" in the DSM classification system. To be more precise, and as indicated in the supporting texts, "the physical disorder should be noted on Axis III" (APA, 1980, p. 265, 1987, p. 73), which described medi$\mathrm{cal} /$ physical conditions relevant in diagnosing and treating a psychiatric disorder. $^{2}$

\section{Inclusion in the Absence of an Exclusion Clause and in the GIDNOS Category}

DSM-III and DSM-III-R also comprised a few residual categories that made no mention of intersex, and thus did not formally exclude but rather permitted the presence of the "physical disorder." These categories were: Atypical GID in DSM-III; GIDAANT and GIDNOS in DSM-III-R. In the DSM-IV editions, the supporting texts would make explicit that the GIDNOS

\footnotetext{
${ }^{1}$ The reason why the initial formulation in DSM-III excluded the presence of intersex, while the same diagnostic label permitted it in the revised edition remains obscure (see Meyer-Bahlburg, 1994, p. 23).

2 The (five) axes and all the Not Otherwise Specified (NOS) categories were eliminated from DSM-5.
} 
Table 1 Intersex/DSD in the DSM

\begin{tabular}{|c|c|c|c|}
\hline DSM & (Sub-)classes & Diagnostic categories & Terms provided for intersex/DSD \\
\hline \multirow[t]{3}{*}{$\begin{array}{l}\text { DSM-III (APA, } \\
\text { 1980) }\end{array}$} & \multirow[t]{3}{*}{$\begin{array}{l}\text { Gender identity disorders } \\
\text { In: psychosexual disorders }\end{array}$} & $\begin{array}{l}\text { Transsexualism [adolescents and } \\
\text { adults] }\end{array}$ & $\begin{array}{l}\text { Criterion D: “Absence of physical intersex or genetic } \\
\text { abnormality.” (p. 264) }\end{array}$ \\
\hline & & $\begin{array}{l}\text { Gender identity disorder of } \\
\text { childhood (GIDC) }\end{array}$ & $\begin{array}{l}\text { "Physical abnormalities of the sex organs are rarely } \\
\text { associated with [GID]; when they are present, the } \\
\text { physical disorder should be noted on Axis III." (p. 265) }\end{array}$ \\
\hline & & Atypical gender identity disorder & $\begin{array}{l}\text { "This is a residual category for coding disorders in gender } \\
\text { identity that are not classifiable as a specific Gender } \\
\text { Identity Disorder." (p. 266) }\end{array}$ \\
\hline \multirow[t]{4}{*}{$\begin{array}{l}\text { DSM-III-R (APA, } \\
\text { 1987) }\end{array}$} & \multirow{4}{*}{$\begin{array}{l}\text { Disorders usually first } \\
\text { evident in infancy, } \\
\text { childhood, or } \\
\text { adolescence }\end{array}$} & $\begin{array}{l}\text { Transsexualism [adolescents and } \\
\text { adults] }\end{array}$ & $\begin{array}{l}\text { "In the rare cases in which physical intersexuality or a } \\
\text { genetic abnormality is present, such a condition should be } \\
\text { noted on Axis III." (p. 74) }\end{array}$ \\
\hline & & $\begin{array}{l}\text { Gender identity disorder of } \\
\text { childhood (GIDC) }\end{array}$ & $\begin{array}{l}\text { "Physical abnormalities of the sex organs are rarely } \\
\text { associated with [GIDC]; when they are present, the } \\
\text { physical disorder should be noted on Axis III." (p. 73) }\end{array}$ \\
\hline & & $\begin{array}{l}\text { Gender identity disorder of } \\
\text { adolescence or adulthood, } \\
\text { nontranssexual type } \\
\text { (GIDAANT) }\end{array}$ & [No mention] \\
\hline & & $\begin{array}{l}\text { Gender identity disorder not } \\
\text { otherwise specified (GIDNOS) }\end{array}$ & [Intersex not listed in the examples] \\
\hline \multirow[t]{3}{*}{$\begin{array}{l}\text { DSM-IV (APA, } \\
\text { 1994) and DSM- } \\
\text { IV-TR (APA, } \\
\text { 2000) }\end{array}$} & \multirow[t]{3}{*}{$\begin{array}{l}\text { Gender identity disorders } \\
\text { In: sexual and gender } \\
\text { identity disorders }\end{array}$} & $\begin{array}{l}\text { Gender Identity Disorder } \\
\text {-GID in childhood } \\
\text {-GID in adolescents and adults }\end{array}$ & $\begin{array}{l}\text { Criterion C. "The disturbance is not concurrent with a } \\
\text { physical condition." (APA, 1994, p. 551, 2000, p. 581) }\end{array}$ \\
\hline & & $\begin{array}{l}\text { Gender identity disorder not } \\
\text { otherwise specified (GIDNOS) }\end{array}$ & $\begin{array}{l}\text { "Examples include: } 1 \text {. Intersex conditions (e.g., androgen } \\
\text { insensitivity syndrome or congenital adrenal } \\
\text { hyperplasia) and accompanying gender dysphoria." } \\
\text { (APA, 1994, p. 552) }\end{array}$ \\
\hline & & & $\begin{array}{l}\text { The DSM-IV-TR phrase is identical except for the addition } \\
\text { of "partial" to "androgen insensitivity syndrome" (APA, } \\
2000, \text { p. 558) }\end{array}$ \\
\hline \multirow[t]{3}{*}{ DSM-5 (APA, 2013) } & \multirow[t]{3}{*}{ Gender dysphoria } & $\begin{array}{l}\text { Gender dysphoria in children } \\
\text { Gender dysphoria in adolescents } \\
\text { and adults }\end{array}$ & $\begin{array}{l}\text { "Specify if: With a disorder of sex development [...]." (p. } \\
452, \text { p. } 453)\end{array}$ \\
\hline & & Other specified gender dysphoria & [No mention] \\
\hline & & Unspecified gender dysphoria & [No mention] \\
\hline
\end{tabular}

category could "be used for individuals who have a gender identity problem with a concurrent congenital intersex condition" (APA, 1994, p. 550, 2000, pp. 580-581). By definition, i.e., by virtue of the exclusion criterion $\mathrm{C}$ ("The disturbance is not concurrent with a physical condition"), individuals with intersex could not be diagnosed otherwise.

The DSM-5 categories of Other Specified Gender Dysphoria and Unspecified Gender Dysphoria resemble, in part, the former GIDNOS category. They can be considered residual categories (indeed, residual categories of the GIDNOS residual category, see Footnote 2), since they also apply when the clinical presentations "do not meet the full criteria for gender dysphoria" (APA, 2013, p. 459). But they are distinct from GIDNOS, as they are less a function of the phenomenology of the "disorder" itself in a patient than of the clinician's latitude to indicate (Other Specified GD) or not (Unspecified GD) to her peers or healthcare providers the reasons why a patient does not meet the full criteria.

\section{Full Inclusion as a DSD Specifier}

Compared to prior editions, the DSM-5 formulation is unprecedented with respect to intersex. The new diagnosis of Gender Dysphoria (GD) — with and without a DSD_involves two major changes. The first is the change in name from intersex to DSD in reference to the new medical terminology adopted in 2006 in the "Consensus Statement on Management of Intersex Disorders" (Hughes, Houk, Ahmed, \& Lee, 2006; Lee, Houk, Ahmed, \& Hughes, 2006). Prior to the Consensus Statement and to DSM-5, the expressions "intersex/intersex conditions" or "intersexuality," often described as "physical" or"somatic," 
were used in the DSM. But the lexical change in DSM-5 from the category of intersex to the DSD terminology adopted in the Consensus Statement is not just an update in nomenclature as we shall see in more detail below.

The second change concerns the new status of intersex as a DSD specifier (in other words, a subcategory or subtype) of the overarching diagnosis of GD. The specifier-with or without a DSD — is meant to convey additional clinical information about the presentation, course, possible special features, etc. of GD in patients who have a DSD and those who have not. But the DSD specifier does not simply provide the clinician with a more specific description of GD, other things being equal.

Prior to DSM-5, as we have seen, the inclusion of intersex in the various diagnostic categories for gender identity "problems" was restricted to certain categories and only possible under particular conditions. Residual diagnoses permitted the presence of intersex in the absence of any precision in this regard (e.g., Atypical GID in DSM-III; GIDNOS in DSM-III-R), although it was sometimes more explicit (e.g., intersex is among the examples cited for GIDNOS in the DSM-IV texts). In and by themselves, specific (as opposed to residual) gender diagnoses were never applicable to intersex. Some of them could apply but only with recourse to Axis III (e.g., GIDC in the DSM-III and DSM-III-R; Transsexualism in DSM-III-R). Most importantly, the first formulation of Transsexualism in DSM-III and of GID in the DSM-IV texts contained an exclusion criterion that ruled out the diagnosis in the presence of intersex.

In DSM-5, the former restrictions or particular conditions under which intersex compared to non-intersex individuals could be diagnosed with a "disorder" in gender identity no longer exist. Further, and I will return to this below, the rationale behind the formal exclusion of intersex from the predecessor of GD, the GID diagnosis, was that the gender identity "problems" of intersex (compared to non-intersex) individuals were not psychiatric conditions. Conversely, physical intersex has become an integral part of a mental "disorder" in DSM-5: with the DSD specifier, the new diagnosis of GD is an overarching category designed to apply directly and equally to individuals with and without a DSD. This formulation, I suggest, is unique and radically new-newer than the much-publicized notions of gender incongruence and gender dysphoria- because the inclusion of a DSD specifier amounts to subsume the physical condition under the mental "disorder." How come?

\section{The Fifth Revision: Historic Points and Key Concepts}

The revision process of the controversial GID diagnosis generated various reactions, criticisms, and alternative recommendations by health professionals, transgender associations, and the lesbian, gay, bisexual, and transgender [LGBT] community at large (De Cuypere, Knudson, \& Bockting, 2010; Knudson,
De Cuypere, \& Bockting, 2010a, b; Vance et al., 2010). According to the GID Subworkgroup, the new diagnosis of GD can be considered a compromise guided by two major but contradictory concerns: the concern to lessen the stigma attached to a psychiatric label for transpeople, which, for some, meant removing the diagnosis from the DSM; and the concern to defend access to healthcare and insurance coverage for surgical and hormonal treatments, especially for those individuals with lesser economic means, which required retaining the diagnosis (Drescher, 2010, 2013; Drescher, Cohen-Kettenis, \& Winter, 2012; MeyerBahlburg, 2010; see also Karasic \& Drescher, 2005). Whether the new formulation is the best answer to this dilemma, and whether it will make a difference for transpeople, or whether it is "just semantics," are questions beyond the scope of this article.

In comparison, the lack of debate about issues of stigma and healthcare issues for people with intersex/DSD is striking: the question of whether intersex should be removed from the DSM or retained in the revised diagnosis or whether intersex conditions should be renamed and reconceptualized in this context as "variations" instead of "disorders" of sex development, ${ }^{3}$ and, most importantly, whether the DSD specifier option would be beneficial or not to the persons concerned was addressed nowhere. With the relative exception of MeyerBahlburg (2010), the reports published by the GID Subworkgroup say very little about intersex/DSD in general or about the related diagnostic category and criteria issues in particular (Cohen-Kettenis \& Pfäfflin, 2010; Drescher, 2010 ${ }^{4}$; Zucker, $\left.2010^{5}\right)$.

\footnotetext{
3 As suggested, for example, by Diamond and Beh (2006) in response to the adoption of the DSD label in the Consensus Statement. On this issue, see also Feder and Karkazis (2008), Hinkle (2006), and Reis (2007).

${ }^{4}$ Drescher (2010) mentioned in passing corrective surgeries on intersex infants as an instance of the medical enforcement of gender binaries in Western societies. However, the implications of such surgeries in terms of mental healthcare or the GID revision were not discussed.

5 It should be noted that the "Proposed Revision to the DSM-IV Diagnostic Criteria for Gender Identity Disorder in Children" by Zucker (2010) is the only DSM-5 report that proposed retaining the exclusion criterion for intersex, but the reason for this specific recommendation is not discussed. However, Zucker's view on the DSD specifieroption was that "debating the DSD was secondary to debating whether or not to delete GID from the DSM-5 in its entirety." He further explained: "I was not prepared to argue for or against a DSD specifier until the subworkgroup made a decision about the larger issue. Personally, I have never had a strong feeling against its inclusion in one form or the other because I have seen many DSD children (and some adolescents or adults) with gender dysphoria who, in many ways, are indistinguishable in phenomenology from non-DSDchildren with GD. So, I disagree strongly with your [the author] assertion about misdiagnosis. DSM is largely agnostic regarding etiology: a rose is a rose, regardless of what causes a plant to be a rose." (K. J. Zucker, personal communication, August 30,2014). On the DSM's so-called agnosticism or "atheoretical" stance towards etiology, see my discussion about a nonpersonal etiological factor for GD (APA, 2013, p. 451) and Posttraumatic Stress Disorder (PTSD).
} 
In the rare cases where intersex/DSD issues were more (Meyer-Bahlburg, 2010) or less (Cohen-Kettenis \& Pfäfflin, 2010) discussed, they were collapsed into considerations about "gender identity variants" (from typical masculinity or femininity) or GID without intersex/DSD. A telling example of this can be found in the report by Cohen-Kettenis and Pfäfflin (2010) on "The DSM Diagnostic Criteria for Gender Identity Disorder in Adolescents and Adults." The authors' single concern about intersex/DSD is "the potential risk [for transpeople] of unnecessary physically invasive examinations to 'rule out' intersex conditions if the [exclusion] $\mathrm{C}$ criterion remain[ed] part of the diagnosis" (p. 503). Such risk should definitely be prevented, but it could have also been prevented with the removal of intersex/DSD from DSM-5. This alternative to the DSD specifier was not discussed. The risk of further stigmatizing intersex/DSD individuals with a psychiatric diagnosis could have been addressed had exclusion criterion $\mathrm{C}$ been removed and replaced by the specifier option in the revised diagnosis. This was not discussed either.

The report by Meyer-Bahlburg (2010) offers another, more elaborate example of the same kind of problem. Meyer-Bahlburg is a psychologist and one of the leading experts in the area of intersex/DSD. He has been involved in the successive revisions of the DSM since DSM-III-R (see Meyer-Bahlburg, 1994, p. 23). As a member of the Subcommittee on GID during the DSM-IV revision process, he authored the report on "Intersexuality and the Diagnosis of Gender Identity Disorder," which argued for the exclusion of intersex from the GID diagnosis (Meyer-Bahlburg, 1994). I will discuss this report in more detail below. Since then, Meyer-Bahlburg has been defending this consistent position for more then 20 years (see Meyer-Bahlburg, 2008, 2009). The only exception, it seems, is his report on "gender identity variants" for the DSM-5 revision (MeyerBahlburg, 2010). For all these reasons, his reference publications and expert positions are of special interest for my overall discussion.

\section{DSD as a Subtype of a Special Category for "Gender Identity Variants" Named Gender Incongruence}

To return to the report by Meyer-Bahlburg (2010), it is noteworthy that DSD issues are not discussed at length (pp. 464-466) or per se, but as examples for a larger argument about the "dilemmas in conceptualizing gender identity variants as psychiatric conditions" (see the subtitle of his report). The dilemma arising from the DSD examples is this: is gender change initiated by individuals with a DSD better conceived of as a "mental disorder" (to be diagnosed with the GIDNOS category) or, rather, as a "correction" of the (wrong) gender assignment at birth (pp. 464-465)? ${ }^{6}$ The DSD examples and the

\footnotetext{
${ }^{6}$ Gender change initiated by intersex individuals has been documented before DSM-III, i.e., before the first formulation of psychosexual
}

related classification problem did not raise the question of removing intersex from the DSM. They served to reconsider the stigmatizing GID definition of gender change in individuals without a DSD in light of the apparently less stigmatizing notions of "gender correction" and "gender identity variants."This argument depends on a transgender-centric conceptualization of "gender identity variants," in which DSD are defined as simple variations on this theme.

As a result, and among the various options Meyer-Bahlburg (2010) considered for the revised diagnosis, he recommended the creation of "a special category for gender identity variants" named Gender Incongruence, where "[i]ndividuals with Gender Incongruence associated with a somatic DSD could be classified as a subtype" (p. 471). The report gave no particular reason why the proposed revision should change the DSM-IV exclusion criterion for intersex to an inclusive one and, further, include intersex/DSD as a subtype in the revised diagnosis as if that were self-evident (pp. 464-466). It is not. Yet, the new diagnosis, renamed GD instead of Gender Incongruence, includes, all the same, the suggestion for a DSD subtype - a specifier in the final text. In contrast, sexual attraction as a long-standing specifier (formerly sexual orientation as a subtype) of gender identity "problems" was removed from DSM-5.

\section{From Gender Incongruence to Gender Dysphoria}

Although Gender Incongruence was not retained as a diagnostic name, it is a key notion of GD. The notion itself is not new and can be traced back to the initial classification of psychosexual "disorders" in gender identity. Since DSM-III, the core feature of gender identity "problems" has been defined as an "incongruence between anatomic sex ["assigned sex" since DSM-IIIR; "assigned gender" in DSM- $\left.5^{7}\right]$ and gender identity" (APA, 1980, p. 261, 1987, p. 71, 2013, p. 452). Two kinds of "deviations" from gender "norms" have always been required to diagnose an incongruence: cross-gender identification and cross-gender role/play/behaviors. In DSM-5, these diagnostic criteria are subsumed under the same (A) set of criteria (see Table 2). Four of these-one in Children (A.1.) and three in Adolescents and Adults (A.4., A.5., and A.6.) — acknowledge that transgender identifications are not limited to the "other gender" but can include "some alternative gender [to either masculine or feminine] different from one's

\footnotetext{
Footnote 6 continued

"disorders" in gender identity. At the time, these changes were, therefore, not defined as mental "disorders," and medical treatment for intersex individuals desiring to change their sex did not depend on a psychiatric diagnosis. Money (1969) considered that such cases were partly due to the parents' ambivalence about the sex assigned to their child at birth, while Stoller (1964) postulated a "silent," "congenital, perhaps inherited, biological force" to account for these situations (pp. 224, 225).

7 In fact, "assigned gender" in DSM-5 means "the sex recorded on the birth certificate." I will return to this below (see also Lawrence, 2014, p. 1264).
} 
Table 2 Gender dysphoria

\section{Diagnostic criteria}

Gender dysphoria in children

A. A marked incongruence between one's experienced/expressed gender and assigned gender, of at least 6 months' duration, as manifested by at least six of the following (one of which must be Criterion A1)

1. A strong desire to be of the other gender or an insistence that one is the other gender (or some alternative gender different from one's assigned gender)

2. In boys (assigned gender), a strong preference for cross-dressing or simulating female attire; or in girls (assigned gender), a strong preference for wearing only typical masculine clothing and a strong resistance to the wearing of typical feminine clothing

3. A strong preference for cross-gender roles in make-believe play or fantasy play

4. A strong preference for the toys, games, or activities stereotypically used or engaged in by the other gender

5. A strong preference for playmates of the other gender

6. In boys (assigned gender), a strong rejection of typically masculine toys, games, and activities and a strong avoidance of rough-and-tumble play; or in girls (assigned gender), a strong rejection of typically feminine toys, games, and activities

7. A strong dislike of one's sexual anatomy

8. A strong desire for the primary and/or secondary sex characteristics that match one's experienced gender

B. The condition is associated with clinically significant distress or impairment in social, school, or other important areas of functioning

Specify if:

With a disorder of sex development (e.g., a congenital adrenogenital disorder such as [...] congenital adrenal hyperplasia or [...] androgen insensitivity syndrome)

Coding note: Code the disorder of sex development as well as gender dysphoria

Gender dysphoria in adolescents and adults

A. A marked incongruence between one's experienced/expressed gender and assigned gender, of at least 6 months' duration, as manifested by at least two of the following:

1. A marked incongruence between one's experienced/expressed gender and primary and/or secondary sex characteristics (or in young adolescents, the anticipated secondary sex characteristics)

2. A strong desire to be rid of one's primary and/or secondary sex characteristics because of a marked incongruence with one's experienced/expressed gender (or in young adolescents, a desire to prevent the development of the anticipated secondary sex characteristics)

3. A strong desire for the primary and/or secondary sex characteristics of the other gender

4. A strong desire to be of the other gender (or some alternative gender different from one's assigned gender)

5. A strong desire to be treated as the other gender (or some alternative gender different from one's assigned gender)

6. A strong conviction that one has the typical feelings and reactions of the other gender (or some alternative gender different from one's assigned gender)

B. The condition is associated with clinically significant distress or impairment in social, school, or other important areas of functioning

Specify if:

With a disorder of sex development (e.g., a congenital adrenogenital disorder such as [...] congenital adrenal hyperplasia or [...] androgen insensitivity syndrome)

Coding note: Code the disorder of sex development as well as gender dysphoria

Specify if:

Posttransition: The individual has transitioned to full-time living in the desired gender (with or without legalization of gender change) and has undergone (or is preparing to have) at least one cross-sex medical procedure or treatment regimen-namely, regular cross-sex hormone treatment or gender reassignment surgery confirming the desired gender (e.g., penectomy, vaginoplasty in a natal male; mastectomy or phalloplasty in a natal female)

Reprinted with permission from American Psychiatric Association (2013)

assigned gender" (APA, 2013, p. 452). This is consistent with the non-dichotomous concept of "gender identity variants" promoted in the more recent clinical literature (e.g., Meyer-Bahlburg, 2010).

Initially, gender incongruence per se was considered a psychiatric condition. Formally, this has not been the case since DSM-IV, although it is DSM-5 which has been lauded for this progressive change. DSM-IV is well known for having tried to formalize a (sometimes controversial) definition of "mental disorders" as a function of their "clinical significance," so as to reduce false positive diagnoses. This new and obligatory criterion redefined gender incongruence as a clinical problem if, and only if, the manifestations were concurrent with "clinically significant distress or impairment in social, occupational, or other important areas of functioning" (Criterion D in DSM-IV and DSM-IV-TR, APA, 1994, p. 551, 2000, p. 581; Criterion B in DSM-5, APA, 2013, pp. 452-453). To use the DSM-5 terminology, gender 
incongruence must be accompanied with gender dysphoria.

Gender Incongruence was the diagnostic name initially recommended for the GID revision, ${ }^{8}$ with the good intention of depathologizing gender identity variance (see again, e.g., Meyer-Bahlburg, 2010). Unintentionally, however, it increased the risk of (over-) diagnosing individuals who experience gender incongruence, but live well with it and are thus not gender dysphoric. For this reason, the World Professional Association for Transgender Health (WPATH) in particular argued instead for a name change to Gender Dysphoria (De Cuypere et al., 2010, pp. 121-122; see also Drescher et al., 2012; Zucker et al., 2013). The very name of the DSM-5 diagnosis reflects the shift in focus from gender incongruence to the decisive criterion (B) for clinical significance, i.e., to gender dysphoria (APA, 2013, pp. 452-453).

\section{Gender Dysphoria in the 1970s: A "Liberal” Concept}

The key notion of gender dysphoria in DSM-5 and the diagnosis itself, I suggest, are conceptually very similar to the initial formulation elaborated by Fisk (1974; see also Fisk, 1973) at the beginning of the 1970s. The diagnostic term of gender dysphoria was designed as a new concept (rather than just an umbrella term) to minimize the relevance of defining a differential diagnosis between four conditions that "many authorities on gender aberrations" considered at the time to be mutually exclusive: transsexualism, transvestism (cross-dressing), homosexuality and "biologic intersex" (Fisk, 1974, p. 387). Clinical attention should be refocused instead, Fisk argued, on the "high level of dysphoria concerning [one's] gender of assignment or rearing" (p. 388). This distinctive symptom defined the valid criterion for approving sex change operations (pp. 386, 389).

The therapeutic agenda behind the newly forged concept was to "liberaliz[e] indications for total gender reorientation"; in other words, to "broaden" the "indications for surgical sex conversion therapy" (pp. 386-389). This agenda should not be romanticized in retrospect. At the time, it was stated explicitly by the "liberal" clinicians in response to the fact that the patients expressing the wish for hormonal and surgical treatments presented themselves as "virtual textbook cases of classical transsexualism" as defined by Benjamin (1966) in opposition to transvestism and homosexuality (Fisk, 1974, p. 388). The introduction of the concept of gender dysphoria was thus fueled with the concern (and the suspicion) that trans narratives were not "authentic" but "rehearsed."

The pro-sex-change-surgeries agenda was also a professional one. The "liberal" clinicians sought to promote a surgical and (neuro)endocrinological behaviorist treatment plan for gender

\footnotetext{
$\overline{8}$ It remains the proposed name in the draft for the forthcoming 11th revision of the International Classification of Diseases by the World Health Organization.
}

identity "problems," in a context where physical treatments for transsexualism were made possible by available technologies of bodily transformation, and increasingly desired by gender dysphoric individuals. Yet, these treatments were still highly controversial in the U.S. compared to Europe, not to say opposed by the majority of their colleagues - mostly by psychoanalysts ( $p$. 390; see also Green \& Money, 1969; for historical discussion, see Hausmann, 1995; Meyerowitz, 2002). The therapeutic and professional agendas were mutually reinforcing. The promoted "liberalization" of indications for sex change operations was accompanied by the "liberal" clinicians' self-promotion as operation gatekeepers - a "mandatory period of trial cross-living" was requested for 12-18 months - and as medical chaperons for post-operative (mostly male-to-female) individuals in "gender rehabilitation" programs, including "grooming clinics" (Fisk, 1974, p. 389).

\section{Gender Dysphoria Against Gender Identity Disorder}

Since the 1970s, one diagnostic feature of gender dysphoria has become more strongly emphasized: the "wish for sex reassignment" expressed by gender dysphoric individuals. Such a wish was an integral part of the initial symptomatology, but it has gained an increased salience over the years. Some gender historians have even argued that it came to function as the decisive criterion for assessing the severity of gender dysphoria (e.g., Hausmann, 1995, pp. 126-127). The following quote drawn from a reference textbook documents this point:

The diagnostic label gender dysphoric is much broader than transsexual. This term is the only one available to refer to the whole gamut of individuals, who at one time or another, experience sufficient discomfort with their biological sex to form the wish for sex reassignment. (Steiner, Blanchard, \& Zucker, 1985, p. 5, emphasis in original).

In the DSM, however, it must be underscored that the various categories for gender identity "problems" have never formalized the expressed wish for sex reassignment as a diagnostic criterion per se for gender dysphoria, even less as a valid criterion for approving sex reassignment surgeries. Rather, the notion of gender dysphoria was used along with the DSM taxonomy, sometimes as shorthand for the B Criterion of the GID diagnosis, i.e., "Persistent discomfort with one's assigned sex or sense of inappropriateness in that gender role (often referred to as 'gender dysphoria')" (Meyer-Bahlburg, 1994, p. 25). During the DSM-IV revision, the Subcommittee on GID even expressed "the desire to uncouple the clinical diagnosis of gender dysphoria from criteria for approving patients for sex reassignment surgeries (SRS)" (Bradley et al., 1991, p. 338, emphasis added).

Gender dysphoria is certainly not a diagnostic term among others in and outside the DSM. I see two main reasons why it could be mobilized effectively against the GID diagnosis as 
an alternative concept during the fifth revision. First, gender dysphoria has been the least disputed term in use among DSM experts on GID, transgender health professionals, and the various actors involved over the last decades. ${ }^{9}$ Second, as a consensual term, gender dysphoria opened up the possibility of reversing the change effected in DSM-IV; in other words, of tentatively re-coupling what had been un-coupled in the context of the fourth revision, i.e., the clinical diagnosis and the approval for sex reassignment surgeries. As already mentioned, the two were coupled in the initial concept with the explicit purpose of broadening the indications for such surgeries (Fisk, 1974); further, gender dysphoria also defined the valid criterion for approving such sex change operations and predict their success (p. 387).

I leave it to the prospective clients to tell us whether the new diagnosis of GD is more or less "liberal" than the initial concept. But it should be underscored that the supporting text relates a person's suffering from gender dysphoria to a non-personal etiological factor despite the self-proclaimed atheoretical stance since DSM-III: "Although not all individuals will experience distress as a result of such incongruence, many are distressed if the desired physical interventions by means of hormones and/or surgery are not available" (APA, 2013, p. 451). This statement has no equivalent in prior editions. If we push the reasoning to its logical conclusion, this means that the conventional relation between diagnosis and treatment is overturned in DSM-5: the problem of the non-access to the available hormonal and surgical treatment is logically—not to say etiologically—prior to the gender dysphoria expressed by a client and diagnosed by the clinician (but not the gender incongruence, which is no longer a psychiatric condition per se). The practical implication of this is then to facilitate access to such treatments when they are desired.

\section{Intersex/DSD as a Specifier of Gender Dysphoria}

According to Hausmann (1995, note 69, p. 227), the diagnostic term of gender dysphoria as defined by Steiner et al. (1985, p. 5; quoted above) "does not include intersexual subjects." If this observation is correct, it would point to a conceptual change from the initial formulation, where intersex was relevant to thinking about gender dysphoria. From a clinical perspective centered on gender dysphoria (instead of differential diagnosis), as we have seen, intersex was not considered differently from transsexualism, transvestism, and homosexuality although Fisk (1974) admitted the need for the clinician to be aware of the physical condition:

\footnotetext{
9 See the Harry Benjamin International Gender Dysphoria Association founded in 1979, now known as the WPATH; the "Interim Report of the DSM-IV Subcommittee on Gender Identity Disorders" (Bradley et al., 1991; Money 1994); the reports by the DSM-5 GID subworkgroup (Cohen-Kettenis \& Pfäfflin, 2010; Drescher, 2010; Meyer-Bahlburg, 2010; Zucker, 2010); the "Response of the [WPATH] to the Proposed DSM-5 Criteria for Gender Incongruence"(De Cuypere et al., 2010), etc.
}

While I would agree that the elucidation of biologic intersex is an essential prerequisite to the treatment of gender disorders, I feel rather strongly (given the experience of the Stanford University gender dysphoria program) that the differential diagnosis aimed at clearly identifying a subgroup of patients termed transsexuals is in many instances a rather non-productive effort. (p. 387).

It seems to me that the idea that the categories of intersex and gender dysphoria have departed from each other over time needs to be qualified. It is rather contradicted by the fact that gender dysphoria has been explicitly used since DSM-IV as a diagnostic term (although not a category) to refer to gender identity "disorders" in the presence of intersex. Indeed, the item "Intersex conditions [...] and accompanying gender dysphoria" was listed among the examples for GIDNOS (APA, 1994, p. 552, 2000, p. 582). Obviously, individuals with intersex could already be diagnosed with gender dysphoria prior to the DSM-5 diagnosis of GD. However, and this is a crucial difference, the term applied precisely only because the physical condition was an exclusion criterion that ruled out the GID diagnosis. For this reason, one could argue that gender dysphoria and GID (rather than intersex as suggested by Hausmann, 1995) were mutually exclusive diagnostic terms relative to intersex in the DSM-IV texts.

The changed status of intersex/DSD from an exclusion criterion to a specifier in DSM-5 does not simply derive from the replacement of GID by a diagnosis named Gender Dysphoria. As previously discussed, GD with a DSD specifier follows the recommendation made by Meyer-Bahlburg (2010) to include DSD as a subtype of a category named Gender Incongruence. However, in addition, I suggest here that intersex was retained in the DSM and came to be conceptualized as a specifier of a mental "disorder" at a particular moment in the history of gender identity "problems": when the controversial GID diagnosis exits the DSM, disorders of sex development enter. This is just one of the many paradoxes that undermine the relevance of the revised diagnosis for individuals with intersex/DSD.

\section{Is Gender Dysphoria an Intersex Condition?}

In February 2010, Organization Intersex International (OII) Australia and OII Aotearoa (New Zealand) addressed a position statement to the APA and WPATH to oppose the proposed revisions for DSM-5 and the seventh revision of the Standards of Care (SOC) that define treatment recommendations for transpeople respectively. ${ }^{10}$ According to OII, the

\footnotetext{
${ }^{10}$ For the initial February 2010 position statement, see https://oii.org. au/6576/organisation-intersex-international-position-statement-dsmvdraft-february-2010/. The submission was updated in June 2012 (Morgan, Wilson, \& O’Brien, 2012).
} 
revisions do not apply to intersex people; they are misconceived and even detrimental to them:

OII Australia and OII Aotearoa have significant concerns about the pathologisation and diagnosis as mentally disordered of intersex people. [...] intersex people are often in a situation where their gender presentation at time of diagnosis with a mental disorder in accordance with the DSM is iatrogenic - it arises from medical treatment. It is [...] essential that the iatrogenic nature of gender-related distress in intersex people is acknowledged. In cases of iatrogenic gender presentation, it is insulting and damaging for people who have been made to more closely conform to an arbitrary binary gender to be told they have a psychiatric disorder or condition if they reject that assignment. (Morgan et al., 2012, pp. 5, 11) ${ }^{11}$

The objection made by OII in the above quote about the iatrogenic nature of gender dysphoria in intersex people points to a crucial difference between individuals with and without intersex/ DSD relative to cosmetic genital surgeries and hormone therapy. Medical treatments are imposed-i.e., carried out without the child's consent ${ }^{12}$ - upon the first group to "normalize" the appearance of the "ambiguous" genitalia at birth or during early infancy according to the treatment plan defined in the 1950s by Money and colleagues (Money, Hampson, \& Hampson, 1955b; for critical discussions, see, e.g., Fausto-Sterling, 2000; Dreger 1999; Karkazis, 2008; Kessler, 1990, 1998; Kraus, Perrin, Rey, Gosselin, \& Guillot, 2008; Swiss National Advisory Commission on Biomedical Ethics, 2012). No such treatments are imposed upon individuals in the second group, although they can sometimes express a wish for such treatments when they grow up, but the timing (non-consensual versus consensual) and purpose ("fixing sex" or transitioning) of the treatments are very different, not to say opposite. Whether some individuals with intersex/DSD want to access the same treatments to change (back or "correct" as some would argue) their gender at an older age, and whether some transpeople just want therapy but no physical treatment, does not disprove this fundamental difference in the clinical management of the two conditions.

This contrasting situation is reflected in their respective activist agendas. Trans activists demand (more open) access to hormone substitution therapy and sex change operations when they are desired by the persons concerned. On the contrary, the central focus of intersex activism has always been to put an end to non-consensual medical treatments, in particular early genital surgeries. ${ }^{13}$ In this

\footnotetext{
${ }^{11}$ For an earlier activist statement about the reasons why GID was not an intersex condition either, see Koyama (n.d.).

12 Technically, "assent" for minors. Ford (2001) discusses "The Fiction of Legal Parental Consent to Genital-Normalizing Surgery on Intersexed Infants."

13 See the agenda of the most influential intersex association over the last 2 decades (1993-2008), the Intersex Society of North America (ISNA; http:// isna.org); see also, e.g., Intersex Initiative (http://www.intersexinitiative.
}

regard, the "Consensus Statement on the Management of Intersex Disorders" (Hughes et al., 2006; Lee et al., 2006) is a major disappointment: the "existing consensus recommendations are uncomfortably nonspecific" (Byne et al., 2012, p. 789 ${ }^{14}$ ) and, in fact, not always very different from Money's treatment plan, especially concerning the opportunity and timing of genital surgery. ${ }^{15}$ This practice is continued and remains one of the most contentious issues from the perspective of the persons concerned and biomedical ethics (see, e.g., Karkazis, 2006; Swiss National Advisory Commission on Biomedical Ethics, 2012).

\section{The Irreducible Difference Between Consensual and Non-consensual Treatments}

The possibility that gender dysphoria in intersex people has something to do with the medical treatments that continue to be routinely imposed on them as newborns or children to "fix" the anatomical problem is conveniently bracketed in DSM-5. This is all the more paradoxical, one could argue, since the new diagnosis clearly indicates a non-personal etiological factor for gender dysphoria in non-intersex/DSD individuals: as we have seen, gender dysphoria is said to result in many cases from the non-access to the desired medical treatments (APA, 2013, p. 451). The clinical reasoning is thus asymmetrical here: there is no logical reason why the same medical treatments could not generate clinically significant distress and impairment, sometimes because these treatments are wanted and not available (gender dysphoria), sometimes because they were initially not wanted but imposed at birth or during early infancy ("iatrogenic" gender dysphoria). The exception would be if one erases the irreducible difference between consensual and non-consensual medical treatments. The DSM-5 text is rather convoluted on this issue:

Most individuals with a disorder of sex development who develop gender dysphoria have already come to medical attention at an early age. For many, starting at birth, issues of gender assignment were raised by physicians and parents. Moreover, as infertility is quite common for this group, physicians are more willing to perform cross sexhormone treatments and genital surgery before adulthood. Disorders of sex development in general are frequently associated with gender-atypical behavior starting in early childhood. However, in the majority of cases, this

Footnote 13 continued org), the Androgen Insensitivity Syndrome Support Group (http://www . aissg.org/), OII International Network (http://oiiinternational.com), Zwischengeschlecht (http://zwischengeschlecht.org), etc.

14 This quote is derived from the section entitled "G[ender] V[ariance] in Persons with Somatic Disorders of Sex Development (Intersexuality)" in the "Report of the American Psychiatric Association Task Force on Treatment of Gender Identity Disorder"(Byne et al., 2012, pp. 786-790).

15 This shows more clearly in Houk and Lee (2008) than in Hughes et al. (2006) or Lee et al. (2006). 
does not lead to gender dysphoria. As individuals with a disorder of sex development become aware of their medical history and condition, many experience uncertainty about their gender, as opposed to developing a firm conviction that they are another gender. However, most do not progress to gender transition. Gender dysphoria and gender transition may vary considerably as a function of a disorder of sex development, its severity, and assigned gender. (p. 456)

This quote (which is essentially the only reference to DSD in the GD chapter) euphemizes the problematic timing and nature of the "medical attention,"i.e., early, non-consensual and appearance-normalizing treatments of atypical genitalia. It also obscures the fact that the whole rationale behind these treatments has always been to maintain and fortify the child in the assigned sex: the child was either "boyed" or "girled" depending on the size of the phallus at birth and the hormonosurgical possibilities of reconstructing "normal" male or female-looking genitalia (Money et al., 1955b; see also Hughes et al., 2006; Lee et al., 2006). In contrast, the aim of trans therapy is not consolidation of the assigned sex, but sex change.

\section{Gender Dysphoria: A Second-Order Diagnosis}

The problem is, in fact, even more acute. In individuals with intersex/DSD, the diagnosis of intersex/DSD and the medical assignment of the child as boy or girl precede-both chronologically and logically, as we have seen — any identifiable gender "problem":

Very rarely are DSD individuals identified as having a gender identity problem before a medical DSD diagnosis has been made. Thus, most DSD individuals who develop GIV [gender identity variance] have already acquired medical "caseness" as DSD beforehand, and for many the gender assignment has been problematized in the eyes of their medical service providers as well as their parents from birth on. By contrast, GIV individuals without DSD usually look normal at birth, undergo routine gender assignment, and come to professional attention because of gender-atypical behavior/identity, not because of gender-atypical primary or secondary somatic sex characteristics. (Meyer-Bahlburg, 2009, p. 228)

In other words, gender dysphoria is a "second-order" diagnosis that depends, conceptually and in practice, on the "firstorder" diagnosis - and the previous medical treatment — of intersex/DSD. Again, this is clearly not the case for non-intersex/DSD individuals.

If one does not minimize the difference between consensual and non-consensual treatment, one understands that the relevant question for intersex/DSD people is not whether the diagnosis of GD is a more or less acceptable compromise between the concern about stigma and the concern to secure the reimbursement and access to medical treatments. The debate about the GID revision was framed in these terms. But, individuals with intersex/DSD did not consent to medical treatments, since they were minors at the time of such treatments. It is for this reason that OII asks why should they endure the added stigma of having a mental "disorder" in the event that they reject, at an older age, their sex assignment.

This question is relevant from the critical perspective of OII Australia and Aotearoa and other intersex associations for two main reasons. First, intersex activists "oppose non-consensual genital 'normalizing' surgeries on intersex children primarily because they are harmful physically, emotionally and sexually, and not necessarily because they might get the gender of the child "wrong"' (Koyama, n.d. ${ }^{16}$ ). They are less concerned about their gender identity than about the right to bodily integrity. Second, gender itself is, in fact, not the real issue: as claimed by ISNA, "intersexuality is primarily a problem of stigma and trauma, not gender." 17 In this respect, and assuming that intersex individuals in need of mental healthcare should be given a psychiatric diagnosis, the DSM provides us, one could argue, with just the right category: PTSD, which has existed since DSM-III. One advantage of this category for intersex/DSD individuals is of course that PTSD is about trauma, and not necessarily gender. The other significant advantage would be that PTSD is the only diagnostic category in the DSM that does not diagnose a mental "disorder," but a "normal reaction to an abnormal situation" (see Fassin \& Rechtman, 2009) — the abnormal situation here being the violence inherent to non-consensual treatments.

\section{Mental Health Care for Intersex as Disorders of Sex Development}

One important reason why the question of stigma and the specific healthcare issues of individuals with intersex/DSD were not addressed during the revision process is the lack of critical discussion about the "Consensus Statement on Management of Intersex Disorders" (Hughes et al., 2006; Lee et al., 2006). First of all, and following the same destigmatizing arguments that favored GD over GID as a diagnostic label, it would have made sense to keep the term "intersex" in DSM-5. All the more so, one could argue, since this term-rather than the co-existing medical categories of hermaphroditism prior to the Consensus

\footnotetext{
$\overline{16}$ As Koyama (n.d.) makes it precise, "most intersex people identify and live as ordinary men and women, and are gay, lesbian, bisexual, or straight." See http://www.intersexinitiative.org/articles/intersex-faq. html.

${ }^{17}$ See the ISNA website: http://isna.org. See also Zwischengeschlecht (http://zwischengeschlecht.org).
} 
Statement-was consistently used in the DSM prior to the fifth revision.

More importantly, the DSD clinical framework promoted in the Consensus Statement makes recommendations for the management of gender identity "problems" in individuals with DSD that are highly compatible with the new formulation of GD with a DSD. The "compatibility" is not limited to the fact that gender dysphoria is the diagnostic term used to qualify the discomfort expressed by some individuals with a DSD in the Consensus Statement. It was also the case of the GIDNOS category in the DSM-IV texts. In the section entitled "Psychosocial management," the Consensus Statement makes explicit that individuals with a DSD who "report significant gender dysphoria" and a persistent "desire to change gender" should be referred to "a specialist skilled in the management of gender change" (Lee et al., 2006, pp. e492-e493).

In practice, this means that the reference framework for intersex/DSD individuals with gender dysphoria is the clinical management of gender identity "disorders" and gender change in non-intersex/DSD individuals. To put it plainly, the consensus recommendations involve "transsexualizing" the gender "problems" in individuals with intersex/DSD, regardless of their distinctive medical histories. Just like the diagnosis of GD, the DSD framework obscures the fact that gender dysphoria can only be a second-order diagnosis in the presence of intersex/ DSD and, additionally, that individuals who are diagnosed with intersex/DSD have non-consensual treatment imposed upon them before they can want, and consent, to another medical treatment to change their gender. The clinical framework proposed in the Consensus Statement does not, however, account for all the problems inherent to the inclusion of DSD in GD.

\section{Classification Effects of Professional Dynamics}

Following the Consensus Statement, the relevant literature continued to emphasize the differences between DSD and GID in terms of diagnosis and treatment:

[T] he differences between these two categories of gender-variant individuals [with DSD and with GID] in phenomenon, context of presentation, etiology, and treatment options are so large that identical diagnoses and treatment approaches are not justified and may actually be detrimental to the individuals in need of care. (Meyer-Bahlburg, 2008, p. 345; see also 2009, p. 231; see also Mazur, Colsman, \& Sandberg, 2007)

Since 2008, there has been no dramatic new evidence in the DSD literature to justify a radical change of opinion about the diagnostic status of intersex in the DSM (see Meyer-Bahlburg, 2010). In this light, there is no particular reason why the similarities between gender "problems" in DSD and nonDSD individuals should have been emphasized for the fifth revision (p. 465), while emphasis was put on the marked differences during the fourth revision (Meyer-Bahlburg, 1994) as we shall see in more detail below.

One reason for such inconsistencies may be related to the organization of labor in the area of mental healthcare for gender "problems":

[I]n terms of the provision of clinical psychosocial and medical services to both categories of patients, there is increasing overlap in professional care personnel, psychosocial assessments methods, selected aspects of medical and psychosocial management, and also in regard to support groups and gender activism. (MeyerBahlburg, 2008, p. 345, see also 2009, p. 231)

This point is particularly relevant, as it draws attention to the professional, institutional, and gender activist dynamics that accompanied the revision of the diagnostic categories and criteria for GD in favor of the inclusion of DSD as a specifier of a mental "disorder."

Historically, psychosexual "disorders" in gender identity in the DSM itself were classified in reference to the well-known studies by Money and his colleagues on "human hermaphroditism" (Money et al., 1955a, b; see also Green \& Money, 1969; Money, 1994), and to the related theory by Stoller $(1964,1968)$ about the establishment of a "core gender identity" in early infancy (for historical discussions, see Hausmann, 1995; Meyerowitz, 2002). However, and as earlier said, the timing and purpose of the hormono-surgical treatments for hermaphroditism/intersex/DSD versus gender identity "disorders" are quite different. For this reason, there is an existing and persisting tension, not to say antagonism - rather than an overlap as assumed by Meyer-Bahlburg (2008) in the above quote-between "support groups and [within] gender activism" that focus on the need to facilitate access to medical treatments or, to the contrary, to put an end to non-consensual treatments. ${ }^{18}$

The increasing professional "overlap" between the clinical management of gender "problems" in individuals with and without intersex/DSD may not fill all the gaps in the apparently self-evident inclusion of DSD in GD. But awareness of this overlap may explain why the report by Meyer-Bahlburg (2009) on "Variants of Gender Differentiation in Somatic Disorders of Sex Development" - solicited this time by the WPATH for the 7th revision of the SOC-is so careful to emphasize crucial differences between the gender identity "problems" in DSD and non-DSD individuals. It is noteworthy that in this context, i.e., in a report addressed to transgender health professionals and focusing on treatment (not diagnostic categories) these differences

\footnotetext{
18 A typical example is ISNA. It was founded in political alliance with feminist, queer, and LGBT struggles for the rights to self-determination, but on the distinctive claim that "intersexuality [was] primarily a problem of stigma and trauma, not gender.”.
} 
were sometimes asserted even more strongly and clearly than in the intersex/DSD literature itself. ${ }^{19}$

Interestingly, and in parallel to the APA GID subworkgroup, the WPATH formed a separate workgroup on DSD (Knudson et al., 2010a, p. 56). But just like the DSM-5 report by Cohen-Kettenis and Pfäfflin (2010) mentioned earlier, the WPATH report on DSD focused on the pros of removing intersex as an exclusion criterion for the revised diagnosis (Richter-Appelt \& Sandberg, 2010). The "Response of the World Professional Association for Transgender Health to the Proposed DSM-5 Criteria for Gender Incongruence" is highly revealing (De Cuypere et al., 2010). Contrary to the position statement that OII Australia and OII Aotearoa (Morgan et al., 2012 ${ }^{20}$ ) submitted to the APA and the WPATH, the latter concludes that the DSD specifier is an improvement for individuals with intersex/DSD:

Adding a specifier of "with or without a Disorder of Sex Development" is an improvement over the need to use the "Not Otherwise Specified" diagnosis because individuals with intersex conditions may have a similar experience regarding their gender identity and may desire corresponding treatment interventions. (De Cuypere et al., 2010, p. 120)

Symptomatically, but not surprisingly, the WPATH—again, contrary to OII - emphasizes the similarities between intersex and transgender experiences and, among these, the purported shared desire to access sex reassignment treatments on the same accounts, i.e., as if gender dysphoria was a first-order diagnosis for intersex/DSD individuals, while it is not. This logical error, I suggest, constitutes the condition of possibility for the diagnostic category and criteria of GD to apply equally to individuals with and without a DSD.

\section{The Risk of Stigma, Misdiagnosis, and Other Classification Problems (DSM-IV to DSM-5)}

Let me now turn to the contrasting expert opinions expressed some 20 years ago in support of the exclusion of physical intersex from the GID diagnosis. This recommendation for exclusion was grounded in clinical reasoning that took seriously the risk of stigma, misdiagnosis, and other classification problems if gender identity "problems" in intersex individuals were diagnosed as psychiatric conditions. These important arguments need to be recalled, since they are discussed nowhere in the DSM-5 revision literature.

\footnotetext{
19 See especially pp. 228-229, 232-234 in Meyer-Bahlburg (2009).

${ }^{20}$ Let's recall here that OII's initial statement was issued in February 2010.
}

\section{Of Apples and Oranges}

During the fourth revision of the DSM, one report was entirely dedicated to "Intersexuality and the Diagnosis of Gender Identity Disorder" with the purpose to outline specific recommendations in this regard (Meyer-Bahlburg, 1994). Contrary to the DSM-5 reports on GID, but consistent with the intersex literature at the time (and until today, as we have seen), the 1994 report underscored the "marked differences between intersex patients with gender identity problems and non-intersex patients with GID" in terms of "prevalence, age of onset or presentation, sex ratio, and associated or predictive factors" (p. 21; see also Meyer-Bahlburg, 2008, 2009). These "marked differences" explained the "difficulties encountered in applying the DSM category and criteria of [GID] to [intersex] patients" (Meyer-Bahlburg, 1994, p. 21). One of these, as seen earlier, is to conceive their desire for gender change as a mental "disorder" rather than a "correction" of the (wrong) gender assigned at birth.

In the context of the DSM-IV revision, this classification problem was not just considered a "dilemma," as MeyerBahlburg (2010) would put it in his DSM-5 report. Rather, it constituted a strong obstacle to the inclusion of physical intersex in GID. Consequently, the 1994 report concluded that "[p]atients with intersexuality or similar medical conditions should be excluded from the GID diagnosis" (Meyer-Bahlburg, 1994, p. 21). This recommendation was favored among four options outlined in the report (pp. 33-36): "1. [C]ontinue the practice of DSM-III-R"; 2. "Use the GIDNOS category for all intersex patients with gender problems"; 3. "Exempt all intersex patients from the GID diagnosis"; 4. "Create a new diagnostic category, Gender Identity Problem [GIP] of Intersexuality." As we are well aware, option 2 was endorsed in DSM-IV and continued in the Text Revision. ${ }^{21}$

Among the respective advantages and disadvantages listed for each option, the following are of particular interest for my discussion. First of all, and compared to the other options, the distinctive advantage of excluding intersex from the specific GID diagnosis (Option 3) was to "avoi[d] the risk of stigmatization of intersex patients with a mental disorder

\footnotetext{
${ }^{21}$ Initially, I wrote that options 2 and 3 were included in DSM-IV, since the final text both included intersex patients in the GIDNOS category (Option 2 in Meyer-Bahlburg, 1994) and excluded them from the GID diagnosis (Option 3). I thought these two options were not necessarily mutually exclusive in the DSM-IV report itself. However, MeyerBahlburg explained that "the recommended Option 3 made it into the DSM-IV Option book, but was overridden subsequently by the Task Force [...] in favor of Option 2" (H. F. L. Meyer-Bahlburg, personal communication, September 10, 2014). It is unclear why the Task Force favored Option 2. Meyer-Bahlburg was not part of the "full Task Force" and did not participate in the final decision. However, if Option 3 was not included in DSM-IV, this means that the recommended option involved removing intersex from DSM-IV. This provides more convincing support for the point I make here and my overall argument.
} 
label" (p. 35). It is noteworthy that the risk of stigma was not only acknowledged as a problem, but also as a risk that had to be prevented. The 1994 report further defined a decisive criterion to discriminate between the four options. The new category of GIP of Intersexuality (Option 4) was rejected at the time precisely on that account: it would effectively stigmatize "all intersex patients with gender problems," since "the gender problem itself w[ould] be labeled a mental disorder, although it $\mathrm{m}$ [ight] not be one" (p. 36). At stake in the concern about stigma was the related concern to avoid misdiagnosis by mistaking apples for oranges.

\section{The Increased Risk of Stigma and Misdiagnosis in DSM-5}

Compared to DSM-IV, I argue that the risk of stigma and misdiagnosis is increased in the new diagnosis of GD. This is also true for the proposed special category of "Gender Incongruence with a DSD subtype" (Meyer-Bahlburg, 2010) which inspired the final formulation, except that the accompanying recommendations "not [to] classify [Gender Incongruence] as a psychiatric disorder per se" and to place it under "Other Conditions that May be a Focus of Clinical Attention" (p. 471) were not followed in DSM-5. The main problem lies elsewhere however.

Unlike the hypothetical category of GIP of Intersexuality (rejected in the 1994 report), GD with a DSD is not a diagnostic category per se, but a subcategory of the overarching diagnosis of GD. This does not mean that the latter is any less problematic than the former. Both define a psychiatric condition and are, according to the DSM-IV reasoning, equally stigmatizing in this regard. But the status of DSD as a specifier accrues the risk of misdiagnosis for intersex/DSD individuals, because the diagnostic criteria for GD are defined for the overarching category and not specifically for individuals with intersex/DSD. These criteria do not take into account the clinical significance of the first-order diagnosis for intersex/ DSD and the previous medical treatment of the physical condition.

The hypothetical category of GIP of Intersexuality certainly had the disadvantage of stigma. However, compared to GD, it also presented at least one advantage: again hypothetically, it would have involved defining specific diagnostic criteria according to the distinctive features and manifestations of gender identity "problems" in intersex/DSD (versus non-intersex/DSD) individuals, which are emphasized in the literature as we have seen-the notable exception of the DSM-5 reports notwithstanding.

\section{A Persisting But Irreducible Classification Problem}

This classification problem emerges in a very concrete manner with GD, where the notion of "gender incongruence" defines the core feature of the diagnosis (APA, 2013, p. 453). In the many various cases of intersex/DSD, the question is of course: how shall we define such "incongruence between one's experienced/expressed gender and assigned gender" (p. 452), and in reference to what? ${ }^{22}$ This question was raised in the 1994 report in the following terms: "In many cases with ambiguous genitalia or with ambiguous secondary sex characteristics or with complicated medical histories, there may be problems to define or justify the sex of reference for GID" (Meyer-Bahlburg, 1994, p. 34; see also p. 35). ${ }^{23}$ Awareness of such problems may explain why DSM-III-R effected a change in wording pertaining to the notion of sex itself. In DSM-III, the essential feature of GID was defined as an "incongruence between anatomic sex and gender identity" (APA, 1980, p. 261). In DSM-III-R, "anatomic sex" was changed to "assigned sex (i.e., the sex that is recorded on the birth certificate)" (APA, 1987, p. 71; see also p. 72). The expression "assigned sex" was continued in the DSM-IV texts.

The shift from anatomy to the question of assignment as the reference term for sex in DSM-III-R is more consistent with the possibility of diagnosing intersex individuals with gender identity "disorders." As seen earlier, this possibility existed for GIDC in DSM-III, and was extended to the diagnosis of Transsexualism in DSM-III-R. Indeed, if the sex of reference is anatomical, identifying an incongruence in intersex individuals is far more problematic than if such incongruence is defined in reference to the "sex recorded on the birth certificate." But the latter conventional definition of sex contains its own problem, since it raises the question of how to assign a sex, and which sex, to intersex individuals. At stake for my present argument is the question of whether intersex individuals can experience any incongruence-not per se, but as defined in the DSM-between their assigned sex and gender identity in the first place. The answer is "yes" if we assume that the assigned sex is correct (for whatever reason), regardless of whether the individual identifies with it when growing up. The answer is "no" if we admit that intersex individuals sometimes seek to "correct" rather than change their assigned sex.

The problem with the sex of reference remains unresolved in DSM-5. One could even argue that the shift in clinical focus from cross-gender identification and behavior to the key notions of gender incongruence and gender dysphoria amplifies the problem. The declared change in wording from sex

\footnotetext{
22 From a different perspective, Lawrence (2014, p. 1264) raises a similar question, but discusses it essentially for GD without a DSD.

${ }^{23}$ Such problems with the sex of reference were considered inherent to two options considered in the report: to continue the practice of DSM-III-R, or to use GIDNOS for all intersex individuals (options 1 and 2 respectively in Meyer-Bahlburg, 1994, pp. 33-35). Again, these options were discarded in favor of the recommendation to exclude individuals with physical intersex from GID.
} 
to gender makes no difference in the matter, although it is offered as a solution to the problem:

In the wording of the criteria, "the other sex" is replaced by "the other gender" (or "some alternative gender"). Gender instead of sex is used systematically because the concept of "sex" is inadequate when referring to individuals with a disorder of sex development. (APA, 2013 , p. 814, emphasis in original)

The novelty of this change is clearly overstated, given that Money (1955) coined the term "gender"_- "gender role" to be more precise (p. 254) - 60 years ago (see also Money et al., $1955 a$, p. 285, b, p. 302). Furthermore, the announced change from sex to gender in DSM-5 is systematically undermined in the supporting text: in the chapter presentation of GD, several notions are clarified, among which the distinction between sex and gender rather than the replacement of sex with gender (APA, 2013, p. 451). The expression "assigned sex" in fact continues to be used in the text (p. 458, emphasis added), a symptomatic error which suggests that gender is perhaps used simply as a synonym of sex (see also Lawrence, 2014, p. 1264). More fundamentally, sex is defined in terms of maleness and femaleness and in reference to reproductive biology, which implies "nonambiguous internal and external genitalia" (APA, 2013, p. 451; see also p. 829). Because of this binary and procreation-centered definition of sex, the concept of sex itself appears unsuited for intersex individuals: they have no sex, but a "disorder of sex development."

This problematic definition of sex brings into critical focus the ways in which the revised diagnosis of GD contains-in the double sense of "hold" and "withhold"-fundamental classification problems that undermine the validity of the diagnosis in its own terms. It is precisely when the classification problem becomes the most serious that we are confronted with an instructive aporia: technically-i.e., not per se, but by virtue of the DSM-5 definition of sex-individuals with a DSD cannot experience "anatomic (in fact, genital) dysphoria." This notion, overlooked in the revision reports, is defined as an "incongruence between experienced gender and somatic sex" (p. 455, emphasis added). This is almost exactly the same definition provided by DSM-III for the essential feature of GID as a subclass (not a diagnostic category as in DSM-IV) of Psychosexual Disorders: "The essential feature of the disorders included in this subclass is an incongruence between anatomic sex and gender identity" (APA, 1980, p. 26). This equivalent formulation is highly instructive: it tells us that gender dysphoria (a term in professional usage since the beginning of the 1970s) is, and has always been from a clinical perspective about anatomic dysphoria (see again Fisk, 1974), and further that anatomic dysphoria is "about sex, not gender" (see Money, 1994, p. 167, emphasis added).

At this point, we need the full definition of "sex" (and "sexual") provided in the chapter for GD: "sex and sexual refer to the biological indicators of male and female (understood in the context of reproductive capacity), such as in sex chromosomes, gonads, sex hormones, and nonambiguous internal and external genitalia" (APA, 2013, p. 451). Given this definition of sex, anatomic dysphoria must be logically restricted to individuals who experience gender dysphoria without a DSD. The logical exclusion of DSD from anatomic dysphoria is the one thing that makes sense in GD, but this exclusion undermines the applicability of all the criteria pertaining to anatomic dysphoria, namely: Criteria A.7. and A.8. for GD in Children; and Criteria A.1., A.2., and A.3. for GD in Adolescents and Adults (see Table 2). One could argue that this leaves us with just the right number of A criteria to diagnose a "marked gender incongruence" in Children (indeed 6 out a total of 8, plus A.1. which is required for this age group), and in Adolescents and Adults (2 out of 6 , none of which is obligatory). While this possibility exists, it is internally contradictory, in particular because the (obligatory) $\mathrm{B}$ criterion for clinical significance refers to the non-access to "cross-sex [sic] hormone treatment or gender reassignment surgery" (p. 453). It does not refer to the nonconsensual "access" to such medical treatments from the 1950 s until now, when an individual has been diagnosed with intersex/ DSD.

Whichever way we look at it, whether we call sex "gender," whether the etiology for gender identity "problems" is said to be psychological (emphasized since DSM-III despite the selfproclaimed atheoretical stance), biological (considered in DSM-5), or biopsychosocial (as promoted in DSM-5), or even whether the diagnostic name and categories are more or less stigmatizing, the problem with the referent for the assigned sex or gender (and not just "the sex of reference,"i.e., which sex for intersex?) is irreducible. There is not one, but two referents for assigned sex (gender in DSM-5). Indeed, the sex recorded on the birth certificate is produced differently depending on whether the newborn (or even the fetus or sometimes the adult individual) is diagnosed or not with intersex/DSD. The reason for this is, again, that intersex defines no sex but a "disorder of sex development," in the medical conception and in DSM-5, a "disorder" that must "fixed."

In the presence of atypical genitalia, the referent for the sex recorded on the birth certificate is medically assigned, often surgically and hormonally, but never without a complete physical exam and numerous tests. In the absence of intersex/ DSD, sex is not assigned in this specific manner-including in a medical setting (the delivery room)_although the practice of "boying" and "girling" a newborn with moretypical genitalia is performative, i.e., a sort of action that "does things with words" (Austin, 1975; Butler, 1990).

Because of past and current practices in the clinical management of intersex/DSD, this difference is irreducible to this day. In the area of mental healthcare, it calls into question the relevance of a psychiatric diagnosis for intersex individuals. In the specific case of the DSM-5 diagnosis, it undermines the 
applicability of the diagnostic criteria for gender incongruence in general (A set of criteria) and for anatomic dysphoria in particular (see above) as well as the decisive B criterion for clinical significance. This testifies to the self-contradictory nature of the terms under which a gender diagnosis can (not) apply to individuals with intersex/DSD.

\section{A Logical Conclusion: Remove Intersex/DSD from the DSM}

In this article, I have analyzed from a historical and conceptual standpoint the problematic ways in which the inclusion of a DSD specifier in the new diagnosis of Gender Dysphoria paradoxically excludes the specific healthcare issues of individuals with intersex/DSD, and the important question of the stigma attached to a psychiatric diagnosis. These issues were said to be central to the DSM-5 revision of the GID diagnosis. In the first step of my line of argument, I have discussed the reasons why they had not been addressed in relation to intersex/DSD. These reasons include, but may not be limited to: the expert silences in the DSM-5 reports; the transgender-centric conceptualization of "gender identity variants"; the uncontroversial and very attractive nature of the concept of gender dysphoria over the years; the overlooked distinction between consensual and non-consensual medical treatments; the unexamined assumption that GD with a DSD is a first-order instead of a secondorder diagnosis; the problematic Consensus Statement recommendations in the area of mental healthcare that involve "transsexualizing" intersex/DSD; and, more broadly, the increasing professional "overlap" between the clinical management of gender identity "problems" with and without intersex/ DSD that exacerbates the existing tensions between transgender and intersex activism regarding the timing and opportunity of hormono-surgical treatments. Thus, I draw the obvious conclusion that the DSD specifier was not an improvement for intersex/DSD individuals compared to DSM-IV.

In the second step of my line of argument, I highlighted a striking contrast in clinical reasoning at a 20-year interval. During the DSM-IV revision process, professionals expressed their concern with the risk of stigma, and consequently rationalized the exclusion of physical intersex from the GID diagnosis. They also engaged critically with the problem of classifying "gender dysphoria" in intersex individuals as a psychiatric condition. One of these was the problem with the sex of reference (which sex for intersex individuals?), which is amplified in DSM-5. Ihave contended that the risk of stigma and misdiagnosis was, in fact, increased in DSM-5 compared to DSM-IV. I have consequently argued that the diagnostic criteria for GD do not apply to intersex/ DSD individuals, because they fail to take into account the irreducible difference between GD with and without intersex/ DSD, i.e., between medically and non-medically assigned sex, and between non-consensual and consensual medical treatments, respectively. Furthermore, the criteria are also flawed on their own terms: these terms are inconsistent, even self-contradictory. The logical conclusion from my analysis is therefore to call for the removal of intersex/DSD from the DSM.

Acknowledgments This paper was first presented at the CRASSH Conference, "Classifying Sex: Debating the DSM-5," 4-5 July 2013, University of Cambridge, U.K. I offered an expanded discussion of my arguments at an invited lecture at the Centre de Recherche Psychanalyse, Médecine et Société (Paris, 19 November 2013). My thanks go here to Laurie Laufer for her kind invitation, and to the discussants, Thamy Ayouch and Vincent Bourseul. I also wish to thank Céline Lefève for inviting me to speak at the Centre Georges Canguilhem about a related issue (Paris, 5 November 2013). This article was written in part when I was a visiting professor at the Institut des Humanités de Paris (IHP)/ Université Paris Diderot-Paris 7 in November 2013. I address my special thanks to Gabrielle Houbre and Fethi Benslama from the IHP for the opportunity to present my work in different contexts, and for the inspiring conversations during that month. Finally, I want to thank Véronique Mottier, Robbie Duschinsky, and Ken Zucker for their incisive remarks and constructive suggestions that helped improve my argument, Heino Meyer-Bahlburg for kindly answering a few questions about the DSM, and Romain Felli for his generous comments on an earlier draft.

\section{References}

American Psychiatric Association. (1980). Diagnostic and statistical manual of mental disorders (3rd ed.). Washington, DC: Author.

American Psychiatric Association. (1987). Diagnostic and statistical manual of mental disorders (3rd ed., rev.).Washington, DC: Author.

American Psychiatric Association. (1994). Diagnostic and statistical manual of mental disorders (4th ed.). Washington, DC: Author.

American Psychiatric Association. (2000). Diagnostic and statistical manual of mental disorders (4th ed., text rev.). Washington, DC: Author.

American Psychiatric Association. (2013). Diagnostic and statistical manual of mental disorders (5th ed.). Arlington, VA: Author.

Austin, J. L. (1975). How to do things with words. Oxford: Oxford University Press.

Benjamin, H. (1966). The transsexual phenomenon: A scientific report on transsexualism and sex conversion in the human male and female. New York: Julian Press.

Bradley, S. J., Blanchard, R., Coates, S., Green, R., Levine, S. B., MeyerBahlburg, H. F., ... Zucker, K. J. (1991). Interim report of the DSMIV subcommittee on gender identity disorders. Archives of Sexual Behavior, 20, 333-343.

Butler, J. (1990). Gender trouble: Feminism and the subversion of identity. New York: Routledge.

Byne, W., Bradley S. J., Coleman E., Evan Eyler, A., Green, R., Menvielle, E. J., ... Tompkins, D. A. (2012). Report of the American Psychiatric Association Task Force on Treatment of Gender Identity Disorder. Archives of Sexual Behavior, 41, 759-796. doi:10.1007/s10508-012-9975-x.

Cohen-Kettenis, P. T., \& Pfäfflin, F. (2010). The DSM diagnostic criteria for gender identity disorder in adolescents and adults. Archives of Sexual Behavior, 39, 499-513. doi:10.1007/s10508-009-9562-y.

De Cuypere, G., Knudson, G., \& Bockting, W. (2010). Response of the World Professional Association for Transgender Health to the 
proposed DSM 5 criteria for gender incongruence. International Journal of Transgenderism, 12, 119-123. doi:10.1080/15532739. 15532010.15509214.

Diamond, M., \& Beh, H. G. (2006). Variations of sex development instead of disorders of sex development [Electronic Letter to Hugues, I. A. et al. (2006). Consensus Statement on Management of Intersex Disorders], Archives of Disease in Childhood. Retrieved from http://adc.bmj.com/content/91/7/554.extract/reply\#archdischild_ el_2460.

Dreger, A. D. (Ed.). (1999). Intersex in the age of ethics. Hagerstown, MD: University Publishing Group.

Drescher, J. (2010). Queer diagnoses: Parallels and contrasts in the history of homosexuality, gender variance, and the diagnostic and statistical manual. Archives of Sexual Behavior, 39, 427-460. doi:10.1007/s10508-009-9531-5.

Drescher, J. (2013). Controversies in gender diagnoses. LGBT Health, 1 , 1-5. doi:10.1089/lgbt.2013.1500.

Drescher, J., Cohen-Kettenis, P., \& Winter, S. (2012). Minding the body: Situating gender identity diagnoses in the ICD-11. International Review of Psychiatry, 24, 568-577. doi:10.3109/09540261.2012. 741575.

Fassin, D., \& Rechtman, R. (2009). The empire of trauma: An inquiry into the condition of victimhood ( $\mathrm{R}$. Gomme, Trans.). Princeton, NJ: Princeton University Press.

Fausto-Sterling, A. (2000). Sexing the body: Gender politics and the construction of sexuality. New York: Basic Books.

Feder, E. K., \& Karkazis, K. (2008). What's in a name? The controversy over 'Disorders of Sex Development'. The Hastings Center Report, 38(5), 33-36.

Fisk, N. M. (1973). Gender dysphoria syndrome (the how, what, and why of a disease). In D. R. Laub \& P. Gandy (Eds.), Proceedings of the second interdisciplinary symposium on gender dysphoria syndrome (pp. 7-14). Stanford, CA: Stanford University Press.

Fisk, N. M. (1974). Editorial: Gender dysphoria syndrome: The conceptualization that liberalizes indications for total gender reorientation and implies a broadly based multi-dimensional rehabilitative regimen. Western Journal of Medicine, 120, 386-391.

Ford, K. K. (2001). "First, do no harm": The fiction of legal parental consent to genital-normalizing surgery on intersexed infants. Yale Law \& Policy Review, 19, 469-488.

Green, R., \& Money, J. (Eds.). (1969). Transsexualism and sex reassignment. Baltimore: Johns Hopkins University Press.

Hausmann, B. (1995). Changing sex: Transsexualism, technology, and the idea of gender. Durham, NC: Duke University Press.

Hinkle, C. (2006). Thank you very much Dr. Diamond [Electronic Letter to Hugues, I. A. et al. (2006). Consensus Statement on Management of Intersex Disorders], Archives of Disease in Childhood. Retrieved from http://adc.bmj.com/content/91/7/554.extract/ reply\#archdischild_el_2460.

Houk, C. P., \& Lee, P. A. (2008). Consensus statement on terminology and management: Disorders of sex development. Sexual Development, 2, 172-180. doi:10.1159/000152032.

Hughes, I. A., Houk, C., Ahmed, S. F., Lee, P. A., \& LWPES/ESPE Consensus Group. (2006). Consensus statement on management of intersex disorders. Archives of Disease in Childhood, 91, 554-563. doi:10.1016/j.jpurol.2006.03.004.

Karasic, D., \& Drescher, J. (Eds.). (2005). Sexual and gender diagnoses of the Diagnostic and Statistical Manual (DSM). New York: The Haworth Press.

Karkazis, K. A. (2006). Early genital surgery to remain controversial. Pediatrics, 118, 814-815. doi:10.1542/peds.2006-1067.

Karkazis, K. A. (2008). Fixing sex: Intersex, medical authority and lived experience. Durham, NC: Duke University Press.

Kessler, S. J. (1990). The medical construction of gender: Case management of intersexed infants. Signs, 16, 3-26.
Kessler, S. J. (1998). Lessons from the intersexed. New Brunswick, NJ: Rutgers University Press.

Knudson, G., De Cuypere, G., \& Bockting, W. (2010a). Process toward consensus on recommendations for revision of the DSM diagnoses of gender identity disorders by the World Professional Association for Transgender Health. International Journal of Transgenderism, 12, 54-59. doi:10.1080/15532739.2010.509213.

Knudson, G., De Cuypere, G. D., \& Bockting, W. (2010b). Recommendations for revision of the DSM diagnoses of gender identity disorders from the World Professional Association for Transgender Health. International Journal of Transgenderism, 12, 115-118. doi:10.1080/15532739.2010.509215.

Kraus, C., Perrin, C., Rey, S., Gosselin, L., \& Guillot, V. (2008). A qui appartiennent nos corps? Féminisme et luttes intersexes. Nouvelles Questions Féministes, 27, 4-15.

Lawrence, A. A. (2014). Gender assignment dysphoria in the DSM-5. Archives of Sexual Behavior, 43, 1263-1266.

Lee, P. A., Houk, C. P., Ahmed, S. F., \& Hughes, I. A. (2006). Consensus statement on management of intersex disorders. Pediatrics, 118(2), e488-e500. doi:10.1542/peds.2006-0738.

Mazur, T., Colsman, M., \& Sandberg, D. E. (2007). Intersex: Definition, examples, gender stability, and the case against merging with transsexualism. In R. Ettner, S. Monstrey, \& A. E. Eyler (Eds.), Principles of transgender medicine and surgery (pp. 235-259). Binghamton, NY: Haworth Press.

Meyer-Bahlburg, H. F. L. (1994). Intersexuality and the diagnosis of gender identity disorder. Archives of Sexual Behavior, 23, 21-40.

Meyer-Bahlburg, H.F. L. (2008). Treatment guidelines for children with disorders of sex development. Neuropsychiatrie de l'enfance et de l'adolescence, 56, 345-349. doi:10.1016/j.neurenf.2008.1003. 1010.

Meyer-Bahlburg, H. F. L. (2009). Variants of gender differentiation in somatic disorders of sex development: Recommendations for version 7 of the World Professional Association for Transgender Health's Standards of Care. International Journal of Transgenderism, 11, 226-237. doi:10.1080/15532730903439476.

Meyer-Bahlburg, H. F. L. (2010). From mental disorder to iatrogenic hypogonadism: Dilemmas in conceptualizing gender identity variants as psychiatric conditions. Archives of Sexual Behavior, 39, 461-476. doi:10.1007/s10508-009-9532-4.

Meyerowitz, J. (2002). How sex changed: A history of transsexualism in the United States. Cambridge, MA: Harvard University Press.

Money, J. (1955). Hermaphroditism, gender and precocity in hyperadrenocorticism: Psychologic findings. Bulletin of the Johns Hopkins Hospital, 20, 253-264.

Money, J. (1969). Sex reassignment as related to hermaphroditism and transsexualism. In R. Green \& J. Money (Eds.), Transsexualism and sex reassignment (pp. 91-113). Baltimore, MD: Johns Hopkins University Press.

Money, J. (1994). The concept of gender identity disorder in childhood and adolescence after 39 years. Journal of Sex and Marital Therapy, 20, 163-177.

Money, J., Hampson, J. G., \& Hampson, J. L. (1955a). Hermaphroditism: Recommendations concerning assignment of sex, change of sex, and psychological management. Bulletin of Johns Hopkins Hospital, 97, 284-300.

Money, J., Hampson, J. G., \& Hampson, J. L. (1955b). Examination of some basic sexual concepts: Evidence of human hermaphroditism. Bulletin of Johns Hopkins Hospital, 97, 301-319.

Morgan [pseud.], Wilson, G., \& O'Brien, M. (2012). Submission on the draft Diagnostic and Statistical Manual of Mental Disorders 5th edition and the World Professional Association for Transgender Health 7th Standards of Care. Retrieved from http://oii.org.au/wpcontent/uploads/downloads/2012/06/OII-Aus+NZ-DSM+SOCSubmission.pdf. 
Reis, E. (2007). Divergence or disorder? The politics of naming intersex. Perspectives in Biology and Medicine, 50, 535-543.

Richter-Appelt, H., \& Sandberg, D. E. (2010). Should disorders of sex development be an exclusion criterion for gender identity disorder in DSM 5? International Journal of Transgenderism, 12, 94-99. doi:10.1080/15532739.15532010.15515181.

Steiner, B. W., Blanchard, R., \& Zucker, K. J. (1985). Introduction. In B. W. Steiner (Ed.), Gender dysphoria: Development, research, management (pp. 1-10). New York: Plenum Press.

Stoller, R. J. (1964). A contribution to the study of gender identity. International Journal of Psychoanalysis, 45, 220-226.

Stoller, R. J. (1968). Sex and gender: The development of masculinity and femininity. London: Karnac Books.

Swiss National Advisory Commission on Biomedical Ethics. (2012). On the management of differences of sex development. Ethical issues relating to 'intersexuality'. Opinion No. 20/2012. Berne: Author.
Vance, S. R, Jr, Cohen-Kettenis, P. T., Drescher, J., Meyer-Bahlburg, H. F. L., Pfäfflin, F., \& Zucker, K. J. (2010). Opinions about the DSM gender identity disorder diagnosis: Results from an international survey administered to organizations concerned with the welfare of transgender people. International Journal of Transgenderism, 12, 1-14. doi:10.1080/15532731003749087.

Koyama, E. (n.d.). Is Gender Identity Disorder an intersex condition? Retrieved from: http://www.intersexinitiative.org/articles/gid.html.

Zucker, K. J. (2010). The DSM diagnostic criteria for gender identity disorder in children. Archives of Sexual Behavior, 39, 477-498. doi:10.1007/s10508-10009-19540-10504.

Zucker, K. J., Cohen-Kettenis, P. T., Drescher, J., Meyer-Bahlburg, H. F. L., Pfäfflin, F., \& Womack, W. M. (2013). Memo outlining evidence for change for gender identity disorder in the DSM-5. Archives of Sexual Behavior, 42, 901-914. doi:10.1007/s1050810013-10139-10504. 